TAO, Vol. 15, No. 5, 857-879, December 2004

\title{
Mass Concentration and Size-Resolved Chemical Composition of Atmospheric Aerosols Sampled at the Pescadores Islands during Asian Dust Storm Periods in the Years of 2001 and 2002
}

\author{
Chung-Shin Yuan ${ }^{1, *}$, Cheng-Chung Sau ${ }^{1}$, Ming-Chung Chen ${ }^{1}$, \\ Ming-Ho Huang ${ }^{1}$, Su-Wen Chang ${ }^{1}$, Yat-Chen Lin ${ }^{1}$, and Chang-Gai Lee ${ }^{1}$ \\ (Manuscript received 21 May 2003, in final form 18 August 2003)
}

\begin{abstract}
This study investigated the mass concentration and size distribution of atmospheric aerosols collected at the Pescadores Islands during Asian dust storm periods in the years of 2001 and 2002. As part of an island-wide Asian dust sampling network covering Taiwan and its surrounding islands, an atmospheric aerosol sampling site was established at Xiaumen, Pescadores Islands since March 2001. Xiaumen was at the northwest tip of the Pescadores Islands located at the center of Taiwan Strait and approximately 110 kilometers from the West Coast of the Taiwan Main Island. The sampling protocol was conducted to collect sea level atmospheric aerosols for further physical and chemical analysis. This study revealed that five Asian dust storms invaded the Pescadores Islands during the sampling campaign. The mass concentration of atmospheric aerosols, particularly $\mathbf{P M}_{2.5-10}$, were 2 - 3 times higher than background levels (i.e., non-Asian dust storm periods). Comparison of hourly $\mathbf{P M}_{10}$ concentration between Xiaumen and ambient air quality monitoring stations in Taiwan indicated that Asian dust storms usually invaded from either the northeast or the northwest and could last for approximately 2 - 4 days. Moreover, Asian dusts could be preliminarily validated in situ by observing the change of their apparent colors from dark gray to light brown. Comparison of hourly $\mathbf{P M}_{10}$ concentration measured at the Pescadores Islands and Taiwan Main Island during the Asian dust storm periods showed that the Asian dust storm invaded Taiwan from either the northwest or the northeast. Increasing both $\mathbf{P M}_{10}$ concentration and coarse particle mode in the size distribution of atmospheric aerosols validated the invasion of Asian dust storms. Significant increase of
\end{abstract}

\footnotetext{
${ }^{1}$ Institute of Environmental Engineering, National Sun Yat-Sen University, Kaohsiung, Taiwan, ROC

* Corresponding author address: Prof. Chung-Shin Yuan, Institute of Environmental Engineering, National Sun Yat-Sen University, Kaohsiung, Taiwan, ROC; E-mail: ycsngi@mail.nsysu.edu.tw
} 


\begin{abstract}
$\mathrm{SO}_{4}{ }^{2-}, \mathrm{Cl}^{-}, \mathrm{Na}^{+}, \mathrm{NH}_{4}{ }^{+}, \mathrm{Mg}^{2+}$ and $\mathrm{Ca}^{2+}$ concentration on coarse particle mode was also observed for Asian dusts. This suggested that not just natural soil dusts but also anthropogenic pollutants and oceanic spray could accompany the Asian dust storms and arrive at the Pescadores Islands.
\end{abstract}

\title{
(Key words: Asian dust storm, Atmospheric aerosol sampling, Mass concentration, Particle size distribution, Invasion route, The Pescadores Islands)
}

\section{INTRODUCTION}

Asian dust storms were originally blown from inland arid and semi-arid areas located in Northwest China and Mongolia in Asian continent (Uno et al. 2002). The degeneration of fragile ecosystem in those areas is mainly due to over-agricultural cultivation and over-grazing, which has resulted in the emission of immense amount of soil dusts into the atmosphere, characterized as Asian dusts (Zhang and Wang 2001). Asian dusts could be transported easterly from their sources to west pacific countries such as Korea, Japan, and Taiwan (Kagawa et al. 2001; Peng et al. 2002; Chou et al. 2004; Lin et al. 2004). This could have significant environmental effects, including ambient air quality deterioration, atmospheric visibility impairment, radiation energy reduction, mineral deposition, and acid rain neutralization (Zhang and An 1999; Terada et al. 2002; Chen et al. 2004).

During Asian dust storm periods, significant increase of atmospheric aerosols, particularly $\mathrm{PM}_{10}$, have been observed in Taipei, Taichung, Tainan, Kaohsiung, and Pingdon, in Taiwan (Chang and Yang 2002; Liu and Yuan 2000; Liu et al. 2002; Tsuang et al. 2002; Wang et al. 2002). While Asian dust storms frequently invade North Taiwan, they seldom arrived in South Taiwan during recent decades (Liu 2002; Wang et al. 2002; Lung et al. 2004; Hsu et al. 2004). Yellow rain episodes were reported in Japan and Taiwan at the end of March 2000 (Sun 2000; Ma et al. 2001). The morphology and apparent color of dust particles filtered from the yellow rain were similar to yellow sands at their source, the Yellow Soil Plateau in China (Ma et al. 2001). Furthermore, results obtained from the investigation on source apportioning atmospheric aerosols at an Asian dust episode in metro Kaohsiung indicated that the percentage of fugitive dusts increased significantly from $8.5 \%$ (regular periods) to $26.2 \%$ (Asian dust storm periods) (Liu and Yuan 2000).

As reported by previous studies (Chang and Yang 2002), Asian dusts are transported to Taiwan usually, but not necessarily, by strong northward monsoons. This explains why previous investigations conclude that Asian dust storms have invaded Taiwan from January to May during the past decades because strong northward monsoons mainly occurred from early winter to late spring. It would be, therefore, important to sample Asian dusts at sea level and ground level as well as in the atmosphere on their transportation route to Taiwan. Asian dusts have been sampled at Che-ju Island in the Yellow Sea and Tokchok Island in the Sea of Japan (Lee at al. 2001; Kagawa et al. 2001). Measurement of atmospheric aerosols at these islands has provided reliable data for estimating the flux of Asian dust transportation over the ocean. However, only a few sampling campaigns were being conducted at Taiwan's surrounding 
islands, such as that at Lanyu Island in 2001, which was a short-term measurement of $\mathrm{PM}_{2.5}$. In these studies, the measurements of atmospheric aerosols focused mainly on the variation of mass concentration and chemical composition. However, the size distribution and size-resolved chemical composition of Asian dusts have not yet been thoroughly performed. Therefore, it might be worthwhile to establish an Asian dust sampling station at the surrounding islands, particularly at Pescadores Islands in Taiwan Strait.

In reviewing of the survey and investigation of Asian dust storms, it was found that most studies have been conducted in major cities of Taiwan, and just a few sampling protocols have been conducted on its surrounding islands. Therefore, this study aimed to sample Asian dusts on Taiwan's surrounding islands and to investigate the characteristics of sampled atmospheric aerosols. As part of an island-wide Asian dust sampling network covering Taiwan and its surrounding islands, an atmospheric aerosol sampling site was established at Xiaumen, the northwest tip of the Pescadores Islands, since March 2001. The Asian dust sampling campaign was sponsored originally by National Science Council (NSC) in the year of 2001 and was then co-sponsored by Academia Sinica and Taiwan Environmental Protection Administration (TEPA) from the spring of 2002. The Pescadores Islands located at the center of the Taiwan Strait, are approximately 110 kilometers away from the West Coast of Taiwan. In comparison with the other six Air Quality Zones (AQZ) in Taiwan, the Pencardores Islands are characterized as the least polluted Air Quality area (Taiwan Power Company 2003). Due to its clean atmosphere, the Pescadores Islands can be treated as one of the best air quality background sites in Taiwan. Most important of all, no ambient air quality station on the Pescadores Islands has been operated by TEPA till now.

\section{METHODOLOGIES}

\subsection{Sampling Location}

An Asian dust sampling network, including six sampling sites (Wanli, Taipei, Taichung, Tainan, Pingdong, and Pescadores Islands), was established in Taiwan and its surrounding islands for this particular study. As part of the sampling campaign, an Asian dusts sampling site was originally established at the Pescadores Islands that is located in the center of Taiwan Strait (Fig. 1). The Pescadores Islands are regarded as an air quality background site, since there are only a few anthropogenic sources on the Islands. In this study, Asian dusts were sampled at Xiaumen located on the northwestern tip of the Pescadores Islands since March 2001. The Xiaumen sampling site was surrounded by uncultivated grassland with no fugitive dust emission sources near by. The sampling site was approximately a half kilometer away from the coastline and about fifty meters above sea level. In this study, both regular and intensive sampling protocols were conducted to collect sea level atmospheric aerosols during Asian dust storm periods in the years of 2001 and 2002.

\subsection{Sampling Methods}

The Asian dust sampling campaign was conducted since March 2001, which was spon- 
sored originally by NSC and was then co-sponsored by Academia Sinica and TEPA from 2002. In the year of 2001, a regular sampling of atmospheric aerosols was conducted with an IMPROVE-equivalent international aerosol sampler $\left(\mathrm{PM}_{-2.5}\right)$ and a Beta-ray monitor $\left(\mathrm{PM}_{10}\right)$ from March to May. While, in the year of 2002, atmospheric aerosols were collected with an IMPROVE-equivalent international aerosol sampler $\left(\mathrm{PM}_{-2.5}\right)$, a dichotomous sampler $\left(\mathrm{PM}_{2.5}\right.$ and $\mathrm{PM}_{2.5-10}$ ), and a high-volume sampler (TSP) from March to April. The particle size range and sampling time of aerosol samplers are summarized in Table 1.

Sea level atmospheric aerosols were consecutively collected for twelve hours. Daytime samples were collected from 8:00 am to 8:00 pm, while nighttime samples were collected
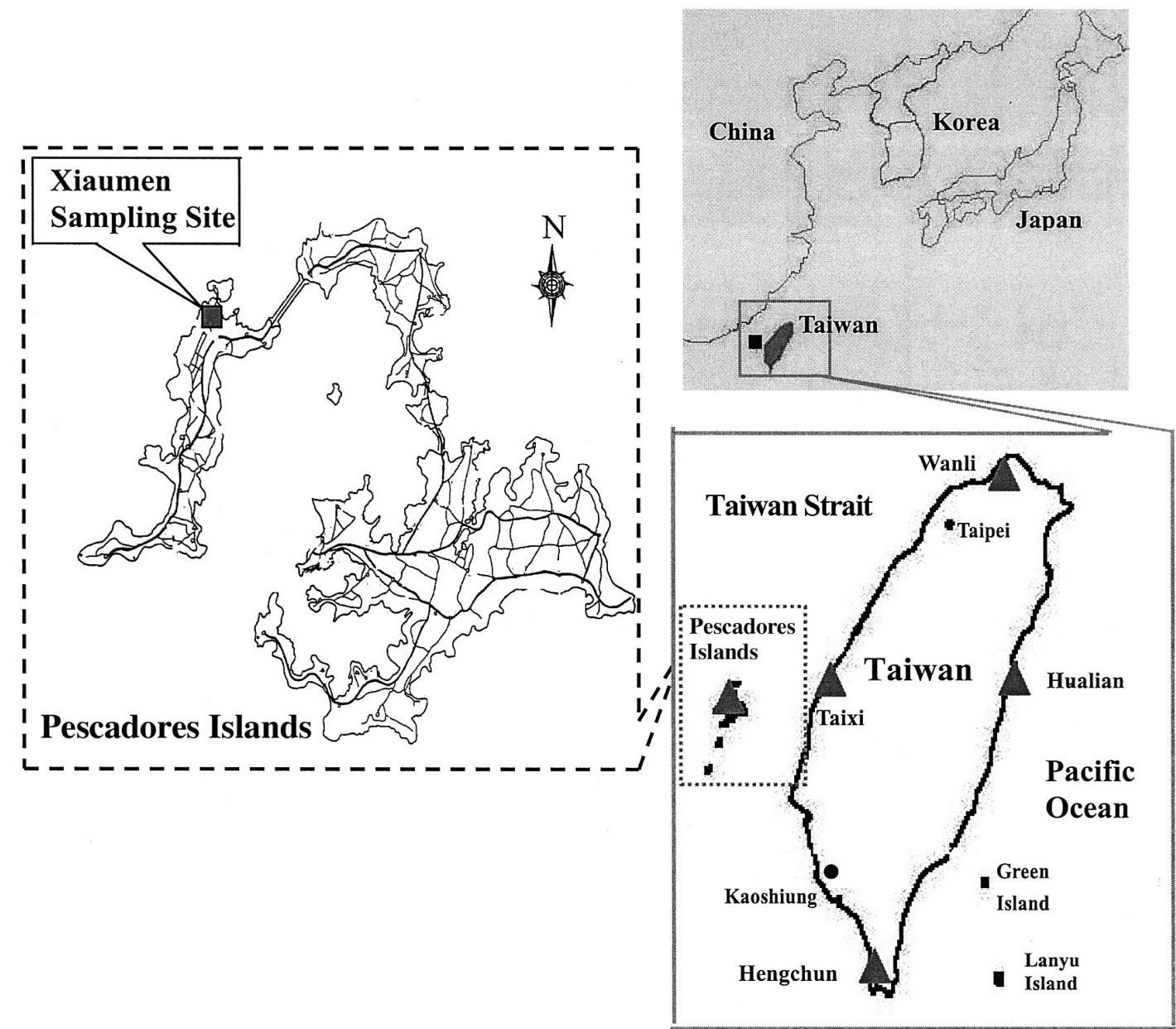

Fig. 1. The location of Asian dust sampling sites located at Xiaumen, Pescadores Islands and in Taiwan over Taiwan Strait. 
from 8:00 pm to 8:00 am. After sampling, filters made of glass fiber or quartz were temporarily stored at $4{ }^{\circ} \mathrm{C}$ environment and then transported to the Air Pollution Laboratory in the Institute of Environmental Engineering at National Sun Yat-Sen University for weighing and further checking the apparent color within one week. Moreover, the hourly and daily concentration of $\mathrm{PM}_{10}$ was further compared with those monitored by Beta-ray monitors at Wanli (North Taiwan), Taixi (West Taiwan), Hengchun (South Taiwan), and Hualian (East Taiwan) ambient air quality monitoring stations (see Fig. 1) for determining the probable invasion route of Asian dust storms.

\subsection{Particle Size Distribution}

During Asian dust storm episodes, size-segregated aerosol samples at the Pescadores Islands were collected with a micro-orifice uniform deposit impactor (MOUDI). The MOUDI sampler consisting of ten stages could collect aerosol particles with cut-off diameters ranging from 0.056 to $18.0 \mu \mathrm{m}$, respectively. Aerosol particles deposited on quartz filters at each stage were then prepared for further chemical analysis. Particle size distribution was consecutively measured for twenty-four hours since pre-sampling of atmospheric aerosols at the Pescadores Islands indicated that the concentration of aerosol particles in the atmosphere was pretty low. Low concentration of aerosol particles collected at each stage would cause errors on weighing and thus result in inaccurate size distribution of chemical species.

Table 1. Particle size range and sampling time of aerosol samplers applied for collecting atmospheric aerosols at the Pescadores Islands.

\begin{tabular}{|c|c|c|c|}
\hline Items & Sampler & Brand/Model & Sampling Time \\
\hline TSP & High-Volume Sampler & $\begin{array}{c}\text { KIMOTO, } \\
\text { Model 121-FT }\end{array}$ & $12 \mathrm{hr}$ \\
\hline $\mathrm{PM}_{2.5} / \mathrm{PM}_{2.5 \sim 10}$ & Dichotomous Sampler & $\begin{array}{c}\text { ANDERSEN, } \\
\text { Model Series 241 }\end{array}$ & $12 \mathrm{hr}$ \\
\hline $\mathrm{PM}_{2.5}$ & $\begin{array}{c}\text { Equivalent International } \\
\text { Aerosol Sampler }\end{array}$ & $\begin{array}{c}\text { IMPROVE, } \\
\text { Model } \delta-I A S\end{array}$ & $12 \mathrm{hr}$ \\
\hline $\begin{array}{c}\text { Particle Size } \\
\text { Distribution }\end{array}$ & $\begin{array}{c}\text { Micro-Orifice Uniform } \\
\text { Deposit Impactor (MOUDI) }\end{array}$ & MSP, Model 110 & $24 \mathrm{hr}$ \\
\hline
\end{tabular}




\subsection{Chemical Analysis}

In addition to characterizing the size distribution of atmospheric aerosols, the ionic species of atmospheric aerosols collected on quarts filter at each stage was further analyzed. First of all, the filters were initially rinsed with $20.0 \mathrm{ml}$ D.I. water in a polyethylene (PE) aliquot and were extracted with an ultrasonic vibrator for longer than two hours. After conducting the extraction, solution was filtrated with a $0.45 \mu \mathrm{m}$ cellulose filter and was then analyzed for further chemical composition. In this study, water-soluble ionic species including major anions $\left(\mathrm{SO}_{4}{ }^{2-}, \mathrm{NO}_{3}^{-}\right.$, and $\left.\mathrm{Cl}^{-}\right)$and cations $\left(\mathrm{NH}_{4}^{+}, \mathrm{Na}^{+}, \mathrm{Mg}^{2+}\right.$, and $\left.\mathrm{Ca}^{2+}\right)$ were measured with an ion chromatography (IC; Dionex Model 100).

\subsection{Quality Assurance and Quality Control}

The quality assurance and quality control (QA/QC) for both aerosol sampling and chemical analysis were conducted during the investigation period. Prior to conducting aerosol sampling, the sampling flow rate of each aerosol sampler was carefully calibrated with an orifice calibrator. Both field and transportation blanks were conducted for atmospheric aerosol sampling, while reagent and filter blanks were undertaken for chemical analysis. The square of correlation coefficient $\left(\mathrm{R}^{2}\right)$ of calibration curve for each chemical analysis and measurement was required to be higher than 0.995. Moreover, the method detection limit (MDL) of each analytical instrument was determined as three folds of standard deviation.

\subsection{Backward Trajectory of Asian Dusts}

In this study, a backward trajectory technique was applied to figure out the invasion routes of Asian dusts before they arrived at the sampling sites. The backward trajectories of Asian dust storm episodes were determined by using the meteorological data obtained from the National Oceanic Atmospheric Administration of U.S.A. The three-dimension wind field used for completing the invasion routes was mainly determined by mathematical modeling, especially at oceanic areas where monitoring meteorological data was unavailable. The backward trajectory is useful and has been commonly applied for describing large-scale transportation of air mass. However, it might not be a good technique for determining small-scale transportation of air mass, since there are lots of uncertainties for the estimated meteorological data.

\section{RESULTS AND DISCUSSION}

\subsection{Mass Concentration of Atmospheric Aerosols}

In this sampling campaign, five Asian dust storm episodes were observed at the Pescadores Islands on April 12 - 14 and May 2 - 4 in 2001, and March 7 - 9, 18 - 20, and March 31 - April 1 in 2002, respectively (Fig. 2). The concentrations of atmospheric aerosols during Asian dust storm episodes were 2 - 3 times higher than the background levels. As reported by previous 
researchers (Uno et al. 2002; Liu and Yuan 2000), the concentration of $\mathrm{PM}_{10}$ increased dramatically from its background values of $40-80 \mu \mathrm{gm}^{-3}$ to the peak values of approximately $120-140 \mu \mathrm{gm}^{-3}$. The increase of $\mathrm{PM}_{10}$ concentration was attributed mainly to coarse particles $\left(\mathrm{PM}_{2.5-10}\right)$ during the Asian dust storm periods. Although the concentration of fine particles $\left(\mathrm{PM}_{2.5}\right)$ did not increase as significantly as those of coarse particles, $\mathrm{PM}_{2.5}$ and TSP demonstrated similar trends as $\mathrm{PM}_{10}$ while Asian dust storms invaded Pescadores Islands.

The variation of daily $\mathrm{PM}_{10}$ concentration at the Pescadores Islands was well consistent with ambient air quality data from monitoring stations located in Taiwan (Fig. 3). This study revealed that the Asian dust storm episodes could last for 2 - 4 days at the Pescadores Islands and in Taiwan as well. In comparison with the hourly $\mathrm{PM}_{10}$ concentration measured in Beijing, China (Zhang and Wang 2001), Asian dust storms reached the Pescadores Islands approximately 36 - 72 hours later than Beijing, which concurred with model simulations (Lin et al. 2002).

The concentrations of $\mathrm{PM}_{2.5}, \mathrm{PM}_{2.5-10}, \mathrm{PM}_{10}$, and TSP between Asian and non-Asian dust storm periods were further compared in this study. Table 2 summarizes the concentration range, average, and standard deviation of atmospheric aerosols sampled at the Pescadores

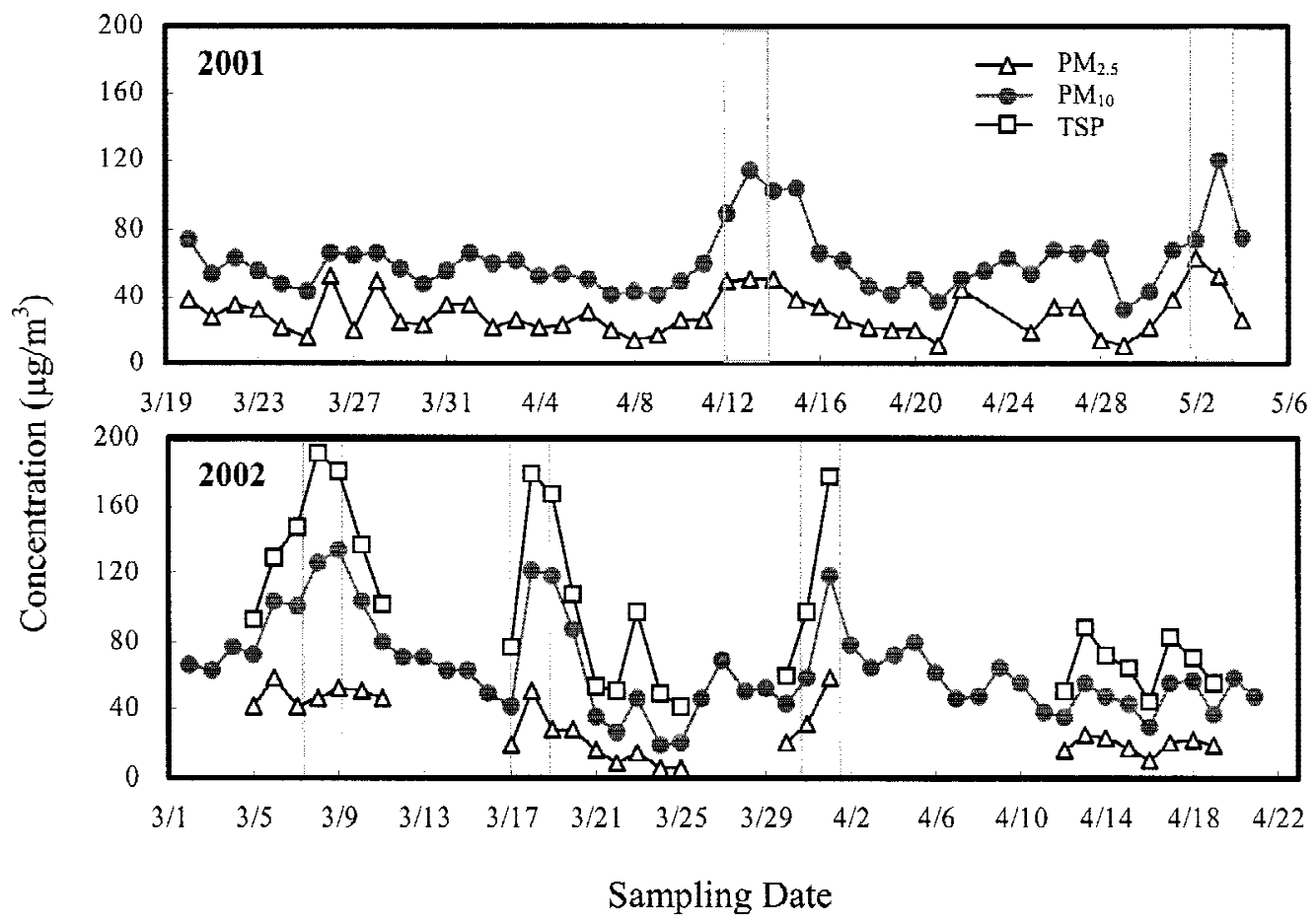

Fig. 2. Variation of $\mathrm{PM}_{2.5}, \mathrm{PM}_{10}$, and TSP sampled at the Pescadores Islands during the Asian dust storm periods in the years of 2001 and 2002. 


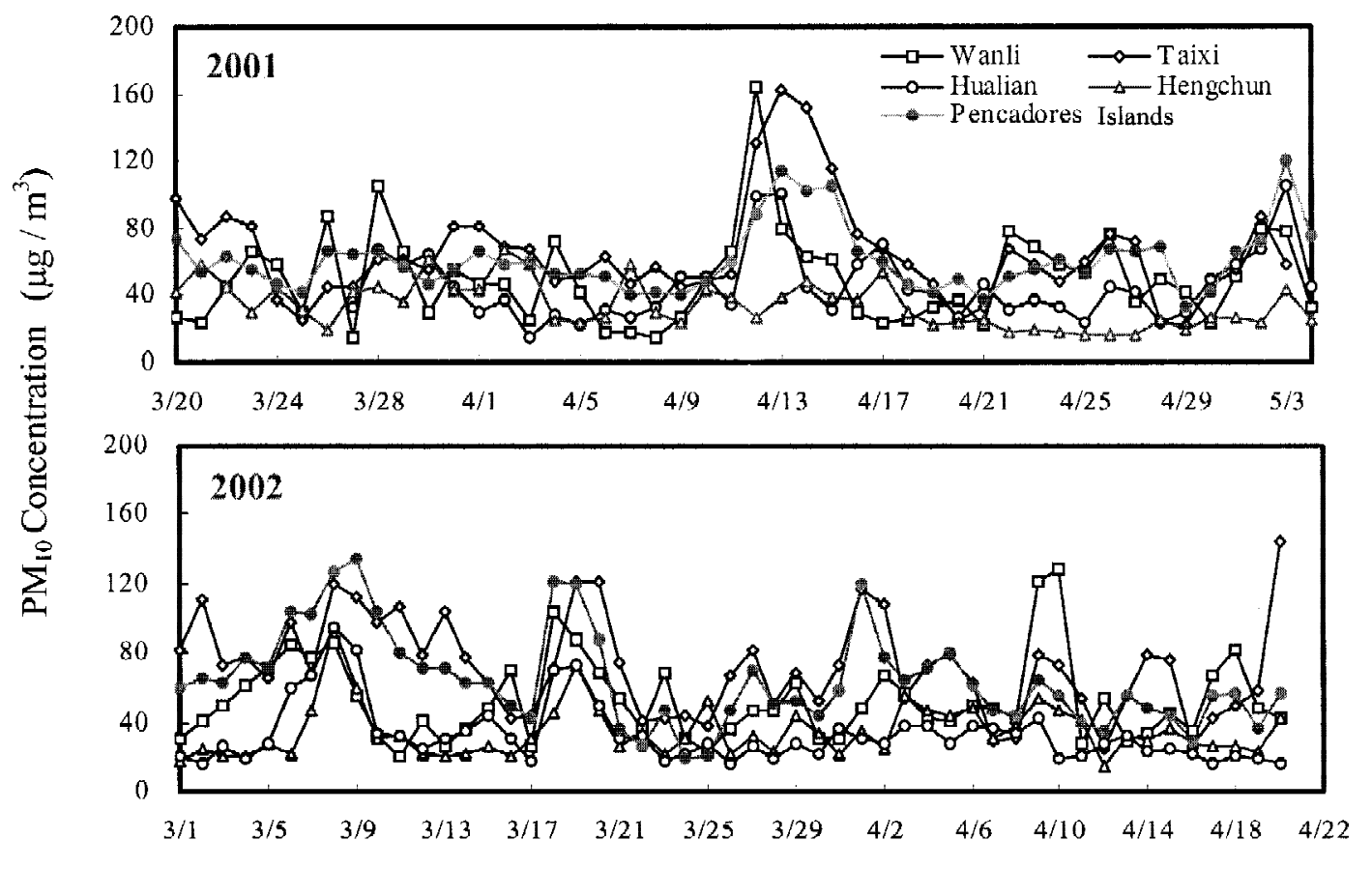

Sampling Date

Fig. 3. Comparison of daily $\mathrm{PM}_{10}$ measured at the Pescadores Islands and in Taiwan.

Islands. Basically, the average concentrations of $\mathrm{PM}_{2.5}, \mathrm{PM}_{2.5-10}, \mathrm{PM}_{10}$ and TSP during Asian dust storm periods were approximately twice higher than during non-Asian dust storm periods. Although the mass concentration of atmospheric aerosols varied, the ratios of $\mathrm{PM}_{2.5} / \mathrm{PM}_{10}$ and $\mathrm{PM}_{10} / \mathrm{TSP}$ between Asian and non-Asian dust storm periods were quite similar. This study revealed that, on average, $\mathrm{PM}_{2.5}$ accounted for approximately 44 $47 \%$ of $\mathrm{PM}_{10}$ while $\mathrm{PM}_{10}$ accounted for approximately $64-69 \%$ of TSP at the Pescadores Islands.

As mentioned in the previous section, the increase of $\mathrm{PM}_{10}$ concentration during Asian dust storm periods was mainly attributed to the increase of coarse particles $\left(\mathrm{PM}_{2.5-10}\right)$. The ratio of coarse particles to fine particles $(\mathrm{C} / \mathrm{F})$ ranged from 0.15 to 3.25 for Asian dust storm periods (Table 2). For non-Asian dust storm periods, the ratio of coarse particles to fine particles $(\mathrm{C} / \mathrm{F})$ ranged from 0.13 to 3.96. The average value of $\mathrm{C} / \mathrm{F}$ for Asian dust storm periods was 1.45 , which was higher than those of 1.29 for non-Asian dust storm periods. However, as illustrated in Fig. 4, the variation of $\mathrm{C} / \mathrm{F}$ was not quite consistent with $\mathrm{PM}_{10}$ concentration. Particularly for episodes occurred on March 25, April 21, 25, and 29 of 2001, high C/F values associated with relatively low $\mathrm{PM}_{10}$ concentration. This suggested that, at the Pescadores 
Islands, $\mathrm{C} / \mathrm{F}$ value might not be a good indicator for validating the invasion of Asian dust storms.

Table 2. The range, average, and standard deviation of atmospheric aerosols sampled during Asian and non-Asian dust storm periods at the Pescadores Islands.

\begin{tabular}{|c|c|c|c|c|c|c|c|c|}
\hline \multicolumn{1}{|c|}{ Particulate Matter } & $\mathrm{PM}_{2.5}$ & $\mathrm{PM}_{2.510}$ & $\mathrm{PM}_{10}$ & $\mathrm{TSP}$ & $\mathrm{PM}_{2510} / \mathrm{PM}_{25}$ & $\mathrm{PM}_{2.5} / \mathrm{PM}_{10}$ & $\mathrm{PM}_{10} / \mathrm{TSP}$ \\
\hline \multirow{4}{*}{$\begin{array}{c}\text { Back- } \\
\text { ground }\end{array}$} & Maximum & 58.2 & 55.4 & 104.0 & 137.2 & 3.96 & 0.88 & 0.81 \\
\cline { 2 - 9 } & Minimum & 5.6 & 5.9 & 19.5 & 41.9 & 0.13 & 0.20 & 0.39 \\
\cline { 2 - 9 } & Average & 25.5 & 27.6 & 53.1 & 76.7 & 1.29 & 0.47 & 0.64 \\
\cline { 2 - 9 } & $\begin{array}{c}\text { Standard } \\
\text { Deviation }\end{array}$ & 11.9 & 9.1 & 16.4 & 29.1 & 0.62 & 0.12 & 0.12 \\
\hline \multirow{4}{*}{$\begin{array}{c}\text { Asian } \\
\text { Dust }\end{array}$} & Maximum & 62.9 & 91.1 & 133.9 & 191.3 & 3.25 & 0.87 & 0.80 \\
\cline { 2 - 9 } & Minimum & 25.5 & 9.6 & 58.9 & 97.9 & 0.15 & 0.24 & 0.60 \\
\cline { 2 - 9 } & Average & 44.3 & 58.7 & 103.0 & 156.2 & 1.45 & 0.44 & 0.69 \\
\cline { 2 - 9 } & $\begin{array}{c}\text { Standard } \\
\text { Deviation }\end{array}$ & 11.7 & 21.0 & 22.3 & 35.1 & 0.70 & 0.14 & 0.06 \\
\hline
\end{tabular}

The units of $\mathrm{PM}_{2.5}, \mathrm{PM}_{2.5-10}, \mathrm{PM}_{10}$, and TSP are $\mu \mathrm{gm}^{-3}$.

\subsection{Invasion Route of Asian Dust Storm}

Further investigation was then conducted on the variation of hourly $\mathrm{PM}_{10}$ concentration at ambient air quality monitoring stations over the Taiwan Strait. In general, the increase of $\mathrm{PM}_{10}$ concentration was initially observed at Wanli, which is located at the northern tip of Taiwan. The concentration of $\mathrm{PM}_{10}$ at other monitoring stations tended to increase gradually from the north to the south. However, for most Asian dust storm episodes, the concentration of $\mathrm{PM}_{10}$ did not increase significantly at the Hengchun monitoring station located at the southern tip of Taiwan. This suggested that the Asian dust storms frequently invaded North Taiwan but seldom arrived South Taiwan.

For an Asian dust storm episode that occurred on April 12 - 13 2001, the concentration of $\mathrm{PM}_{10}$ increased in sequence at Wanli, Taixi, the Pescadores Islands, and Hualian (Fig. 5). This suggested that the Asian dust storm invaded Taiwan from the northwest. However, for an 


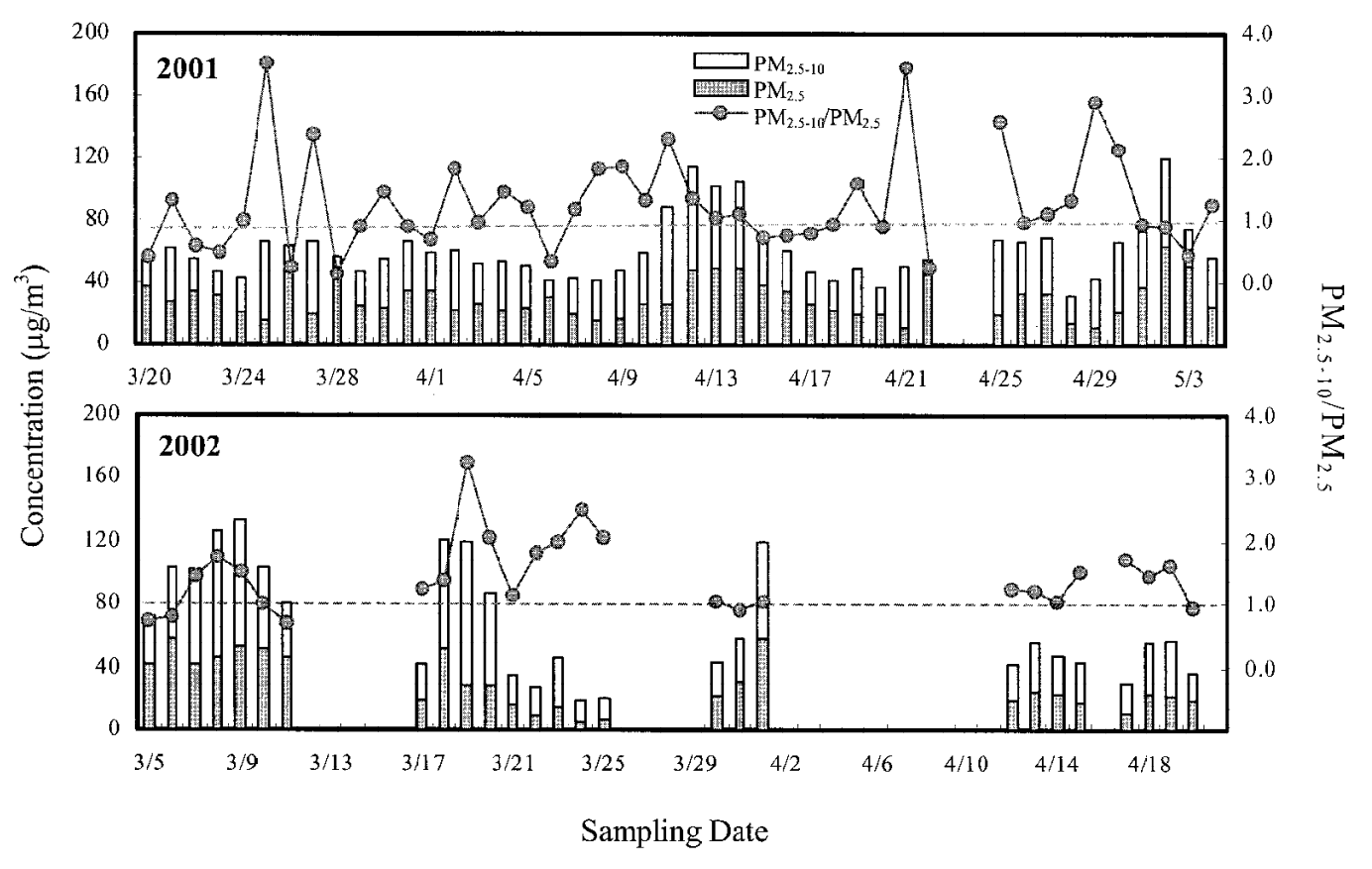

Fig. 4. Ratio of coarse particle mode to fine particle mode $\left(\mathrm{PM}_{2.5-10} / \mathrm{PM}_{2.5}\right)$.

Asian dust storm episode occurred on May 2 - 3, 2001, the concentration of $\mathrm{PM}_{10}$ increased in sequence at Wanli, Hualian, the Pescadores Islands, and Taixi (Fig. 5). It suggested that the Asian dust storm invaded Taiwan from the northeast. The aforementioned two episodes concurred quite well with the backward trajectories obtained from NOAA Website as illustrated in Figs. 6 and 7. In summary, Asian dust storms invaded Taiwan from either the northeast or the northwest in the year of 2001. According to the invasion routes obtained in this study, air mass of Asian dusts might be mixed with local emissions from Taiwan Main Island prior to reaching the sampling site. However, the influence of local emissions on Asian dusts and vise versa are still unclear at this stage. Further researches on source apportionment of aerosol particles sampled at sampling sites are highly recommended in the future.

\subsection{Size Distribution of Atmospheric Aerosols}

The particle size distribution was measured with a ten-stage MOUDI $(0.056-18.0 \mu \mathrm{m})$ at the Pescadores Islands during Asian dust storm periods in the year of 2002. The variations of particle size distribution for three Asian dust storm episodes are illustrated in Figs. 8, 9 and 10. In general, both single- and bi-mode distributions were observed for ambient aerosol particles sampled at the Pescadores Islands. The particle sizes with the highest concentration in fine and coarse particles were $0.56-1.0$ and 3.2 - $5.6 \mu \mathrm{m}$, respectively.

Results obtained from the comparison of particle size distribution and mass concentration of atmospheric aerosols indicated that Asian dust storms contributed mainly on coarse 


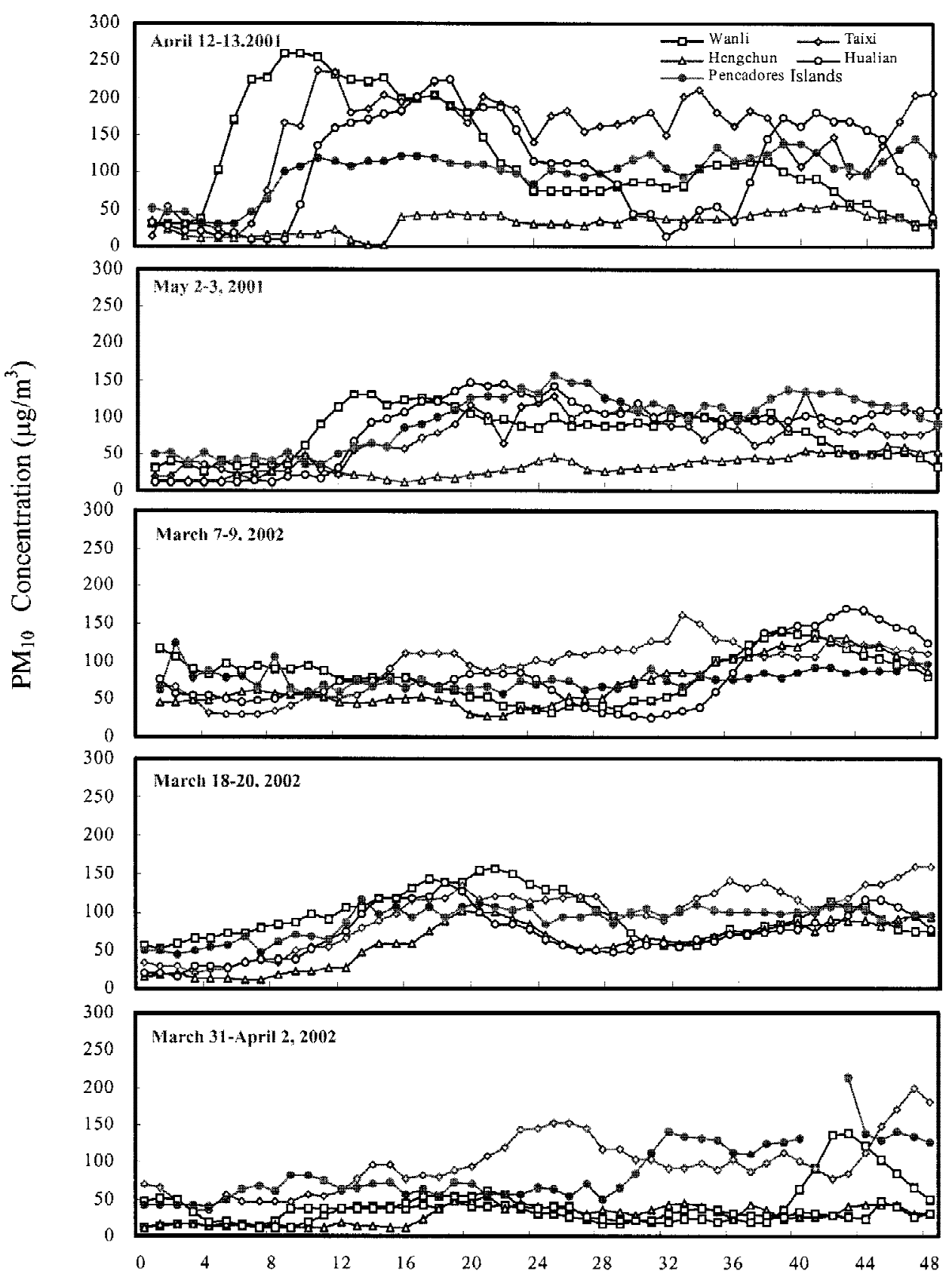

Sampling Time (hr)

Fig. 5. Comparison of hourly $\mathrm{PM}_{10}$ measured at the Pescadores Islands and in Taiwan. 


\section{NATIONAL OCEANIC ATMOSPHERIC ADMINISTRATION Backward trajectories ending at 02 UTC 13 Apr 01 FNL Meteorological Data}

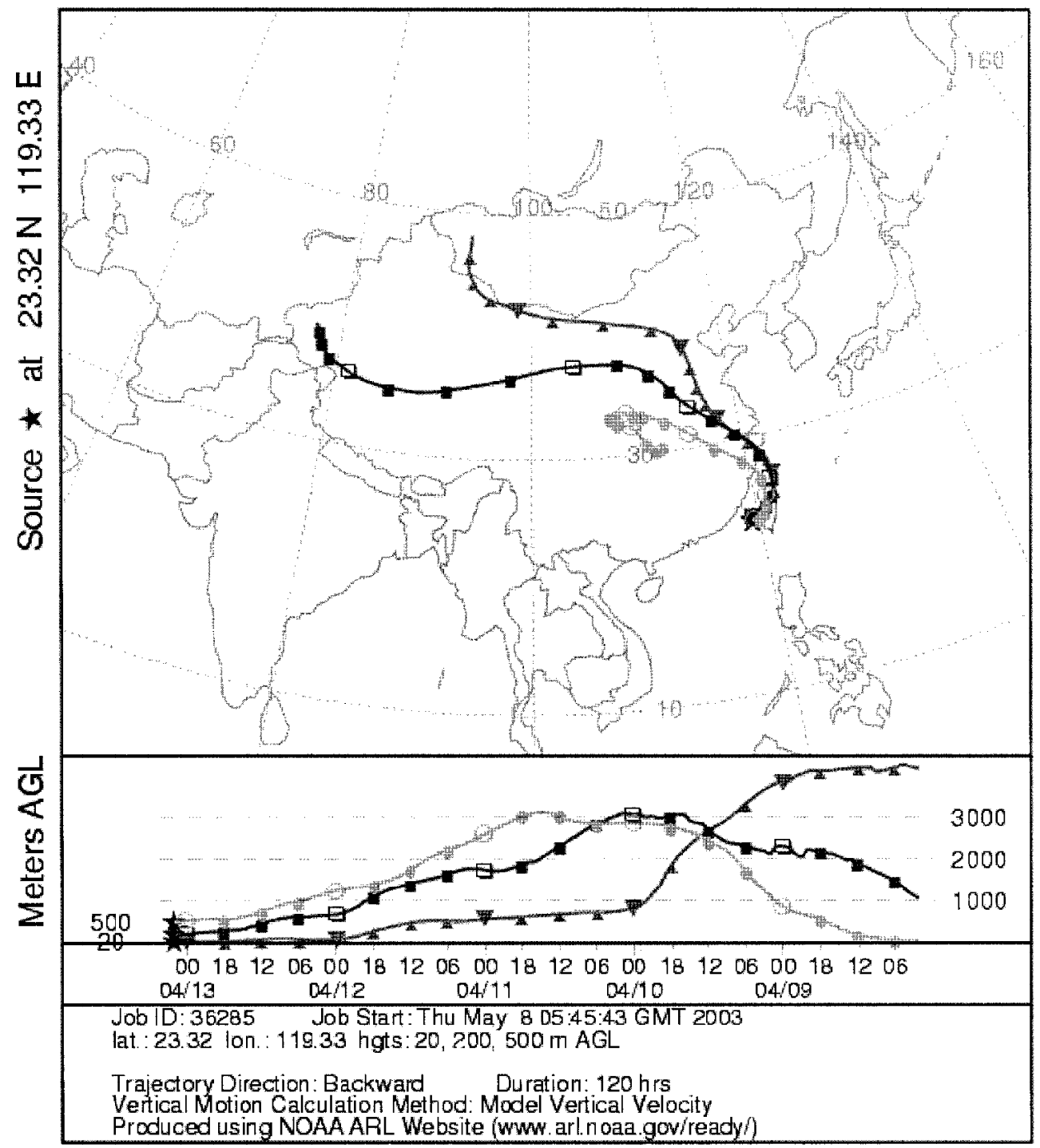

Fig. 6. Backward trajectory of Asian dust storm episode arrived at the Pescadores Islands on April 13, 2001. 


\section{Backward trajectories ending at 00 UTC 03 May 01 FNL Meteorological Data}

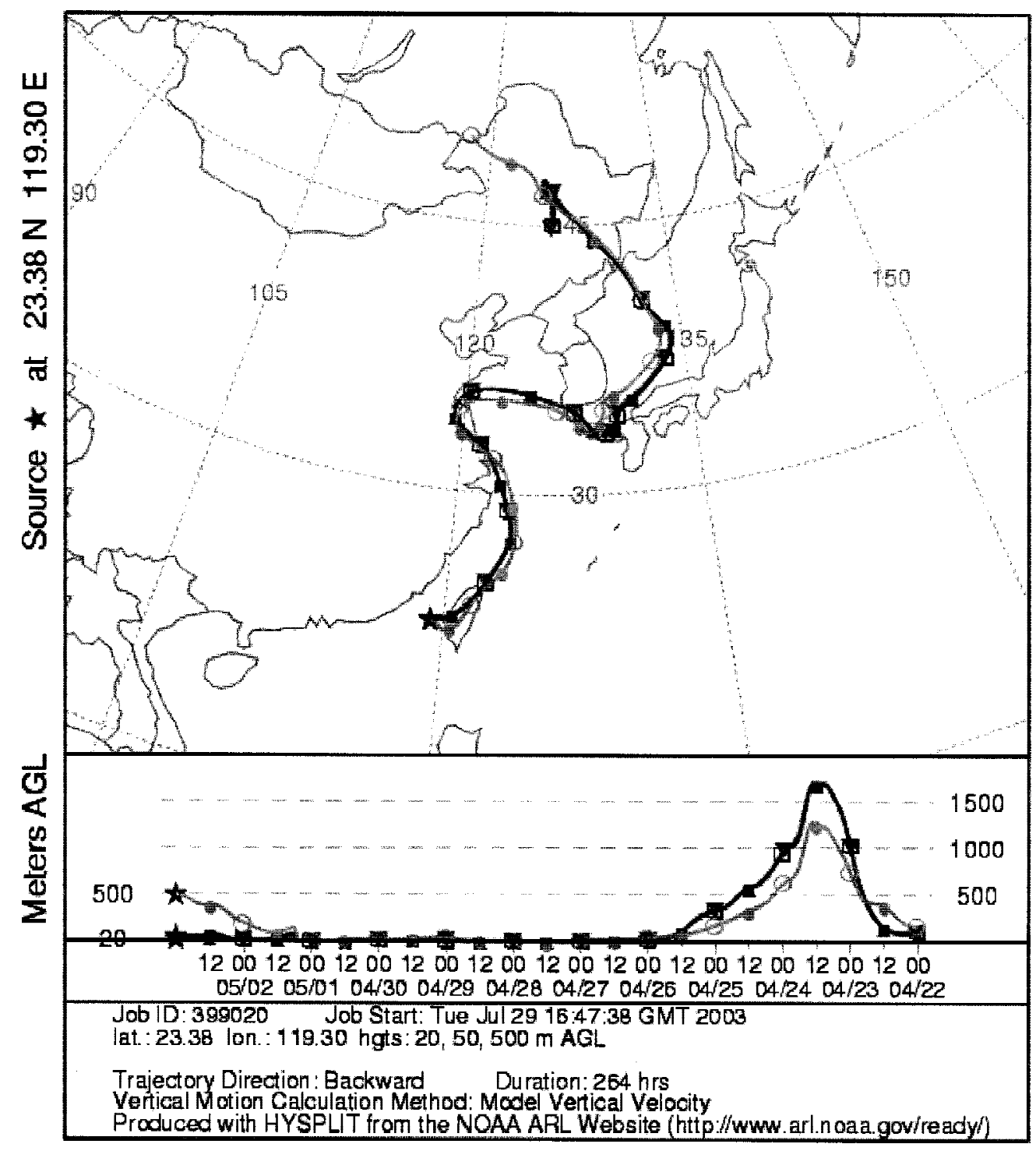

Fig. 7. Backward trajectory of Asian dust storm episode arrived at the Pescadores Islands on May 3, 2001. 


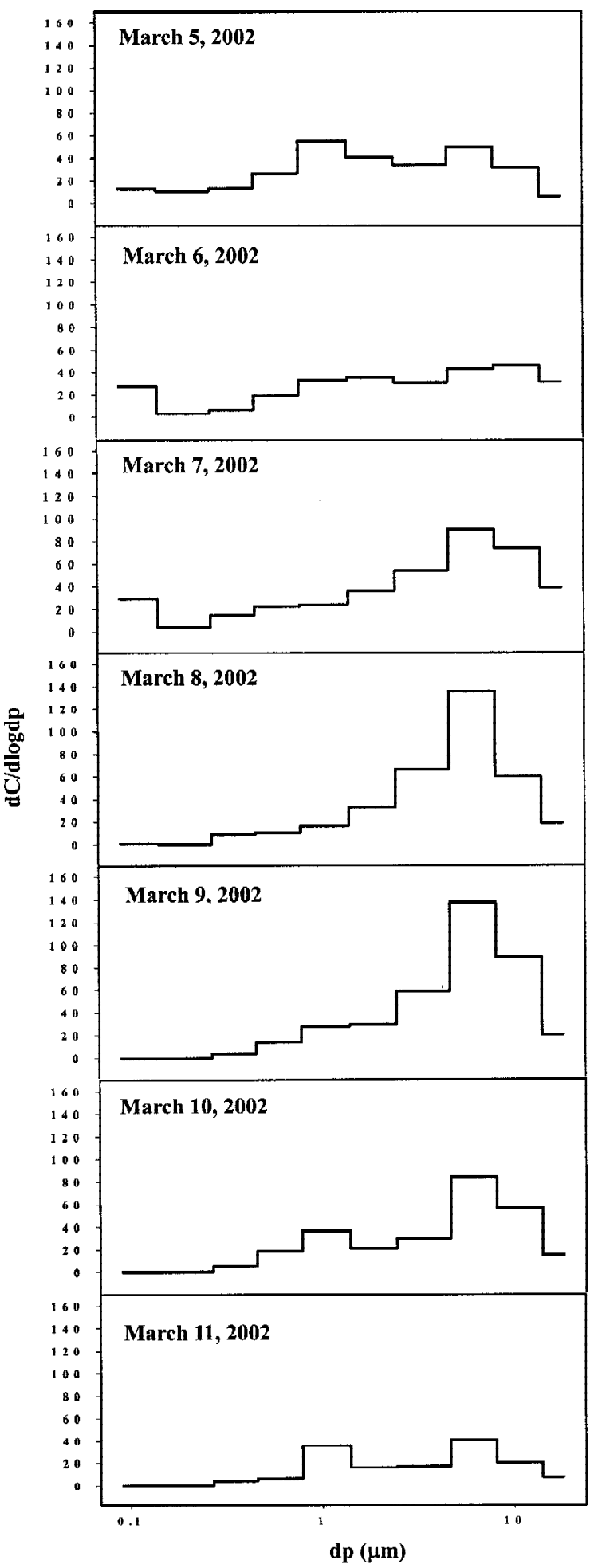

Fig. 8. Size distribution of atmospheric aerosols sampled at the Pescadores Islands on March 5 - 10, 2002. 


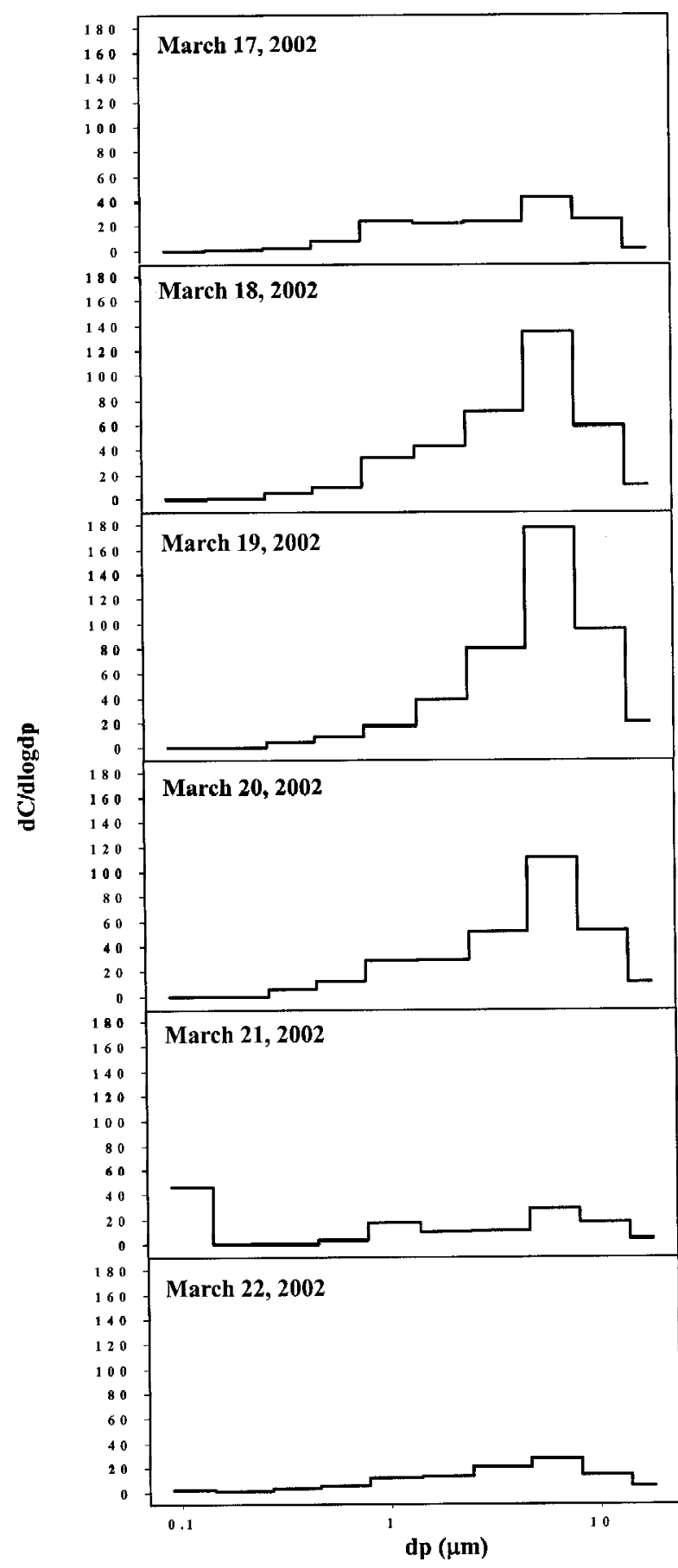

Fig. 9. Size distribution of atmospheric aerosols sampled at the Pescadores Islands on March 17 - 22, 2002. 
spheric aerosol samples collected on March 8 and 11, 2002, representing Asian and non-Asian dust storm periods, respectively, were selected for further chemical analysis of ionic species. Figure 11 illustrates the distribution of $\mathrm{NO}_{3}{ }^{-}, \mathrm{SO}_{4}{ }^{2-}, \mathrm{Cl}^{-}, \mathrm{Na}^{+}, \mathrm{NH}_{4}{ }^{+}, \mathrm{Mg}^{2+}$, and $\mathrm{Ca}^{2+}$ of size-segregated aerosol particles.

The results indicated that $\mathrm{NO}_{3}{ }^{-}$was abundant on coarse particle mode. No significant variation of $\mathrm{NO}_{3}{ }^{-}$distribution was observed between Asian and non-Asian dust storm periods. This was probably due to the fact that $\mathrm{NO}_{3}{ }^{-}$forming from nitrogen oxides was mainly emitted from local sources. The variation of $\mathrm{SO}_{4}{ }^{2-}$ and $\mathrm{NH}_{4}{ }^{+}$size distributions at fine and coarse particle modes was quite consistent. An increase in $\mathrm{SO}_{4}{ }^{2-}$ and $\mathrm{NH}_{4}{ }^{+}$on coarse particle mode during Asian dust storm periods suggested that they could accompany with Asian dusts on their transportation route to Pencardores Islands. One of the most possible chemical species in Asian dusts would be ammonium sulfate $\left[\left(\mathrm{NH}_{4}\right)_{2} \mathrm{SO}_{4}\right]$. Moreover, a significant decrease in $\mathrm{SO}_{4}{ }^{2-}$ and $\mathrm{NH}_{4}{ }^{+}$on fine particle mode was observed. This suggested that local emissions could be diminished by dilution effects of strong northward monsoons. The results also indicated that anthropogenic $\mathrm{SO}_{\mathrm{X}}, \mathrm{NH}_{3}$, and even $\mathrm{NO}_{\mathrm{X}}$ could further chemically react with and/ or physically attach on Asian dusts in the atmosphere as they passed through metropolitan areas. The route of Asian dusts transported to the Pescadores Islands on March 8, 2002 is illustrated in Fig. 12. This shows that the Asian dusts passed through the dense population and intensive industrial areas, metro Beijing and Shanghai in China, prior to arriving the Pescadores Island.

Moreover, a consistent increase in $\mathrm{Cl}^{-}, \mathrm{Na}^{+}$and $\mathrm{Mg}^{2+}$ on coarse particle mode was observed during Asian dust storm periods (Fig. 11). These results indicated that oceanic spray played an important role on atmospheric aerosols at the Pescadores Islands. Strong northward monsoons could cause emissions of sea salt particles due to oceanic spray. Furthermore, a significant increase in $\mathrm{Ca}^{2+}$ on coarse particle mode as well as a decrease on fine particle mode were observed, which further proved that the increase of atmospheric aerosols on coarse particle mode was mainly attributed to crustal materials, namely Asian dusts.

The overall size-resolved ionic species of atmospheric aerosols collected at the Pescadores Islands is illustrated in Fig. 13. Two atmospheric aerosol samples on March 8 and 11, 2002 were compared for Asian and non-Asian dust storms. It appeared that the particle sizes had switched from fine to coarse particle modes during Asian dust storm periods. In general, sulfate was abundant at fine particle mode while nitrate was rich at coarse particle mode. Moreover, the abundance of calcium switched significantly from fine to coarse particle modes. In addition, the unknown portion of Asian dusts distributed on coarse particle mode became even larger while compared to non-Asian dusts. The increase in unknown portion of aerosol particles was probably due to crustal elements, such as calcium, silica and aluminum in soil dusts.

\subsection{Validation of Asian Dust Storms}

In addition to particle size variation of atmospheric aerosols during Asian dust storm periods, the apparent color of aerosol particles was also changed. This study revealed that the apparent color of aerosol particles collected on filters turned from dark gray to light brown for non-Asian and Asian dust storm periods, respectively (Fig. 14). Therefore, at the Pescadores 


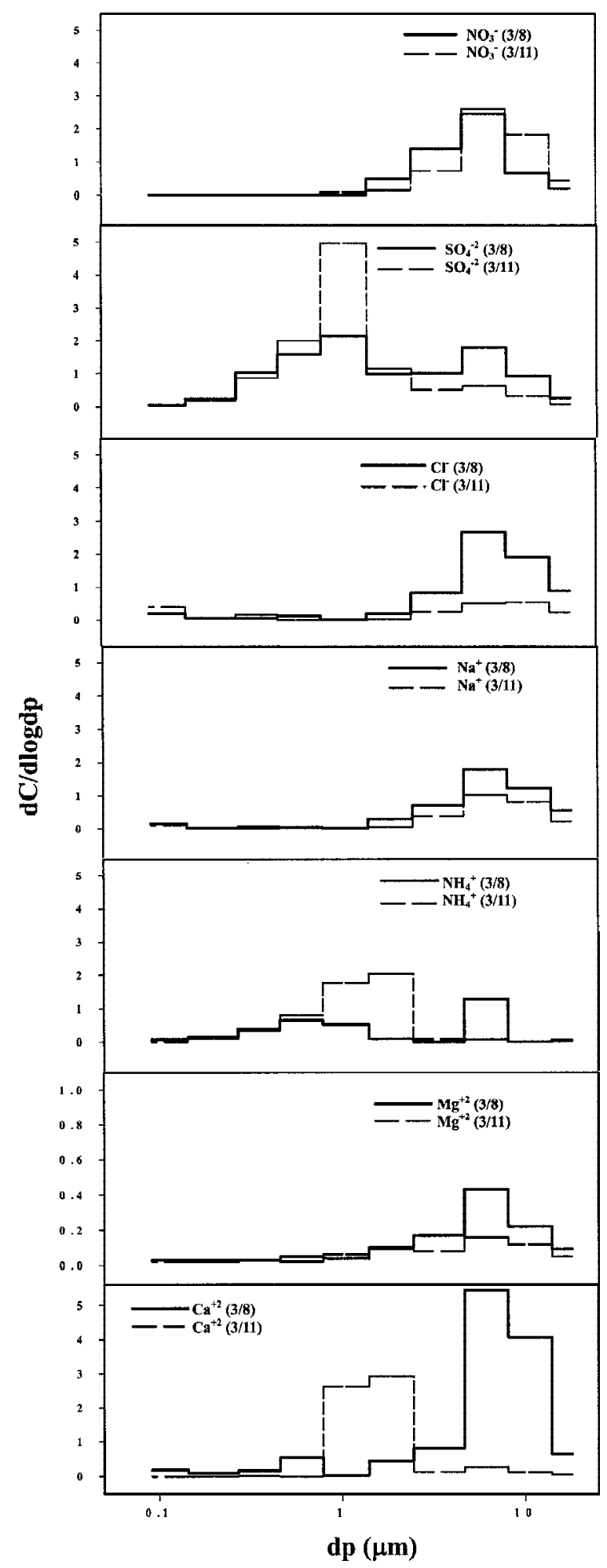

Fig. 11. Size-resolved ionic species of Asian dusts and local aerosols sampled at the Pescadores Islands. 
NATIONAL OCEANIC ATMOSPHERIC ADMINISTRATION Backward trajectories ending at 00 UTC 08 Mar 02 FNL Meteorological Data

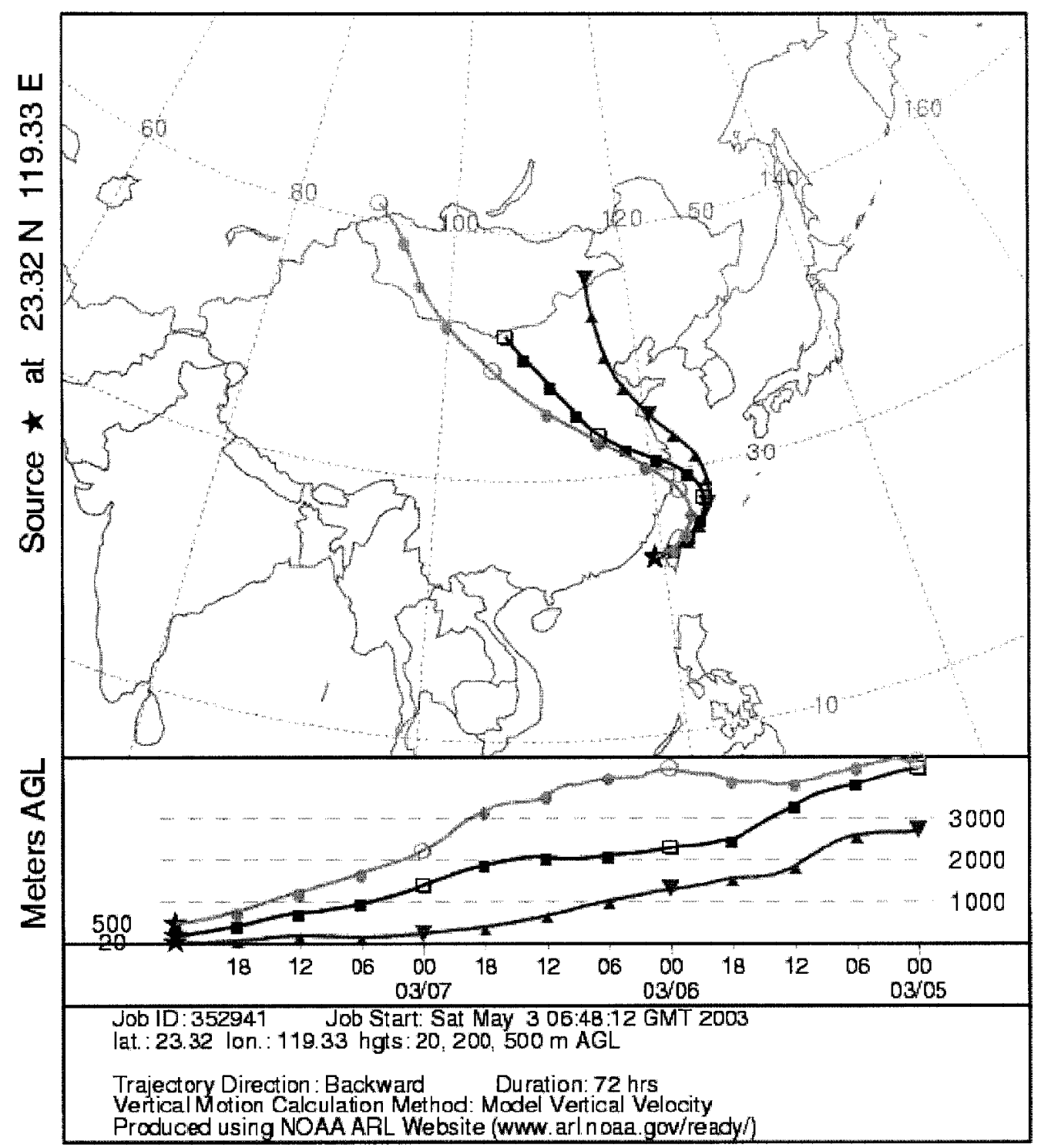

Fig. 12. Backward trajectory of Asian dust storm episode arrived at the Pescadores Islands on March 8, 2002. 


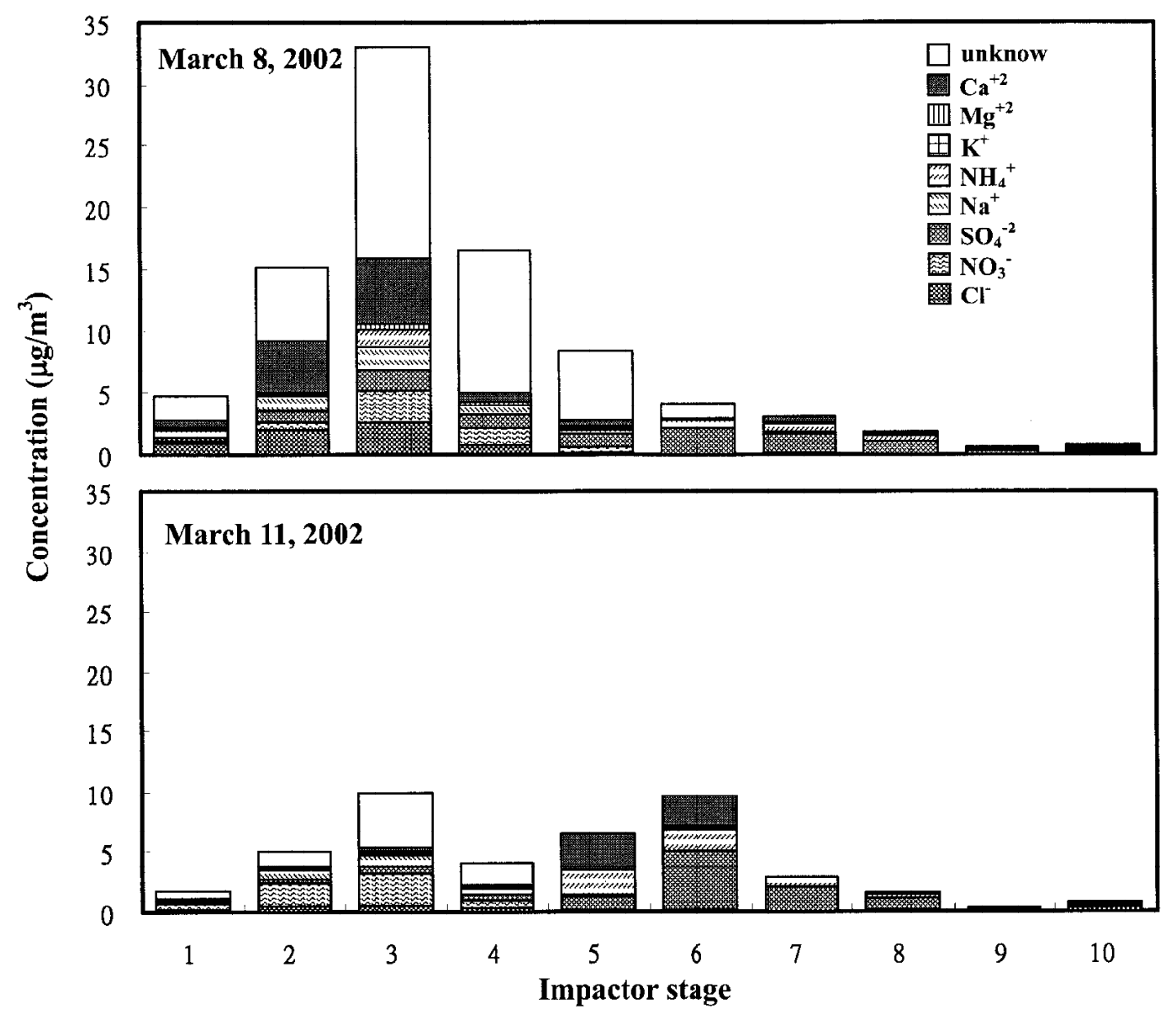

Fig. 13. Overall size-resolved ionic species of Asian dusts and local aerosols sampled at the Pescadores Islands.

Islands, Asian dust episodes can be preliminarily validated in situ by viewing the change of filter's color from dark gray to light brown.

Validation of continental dust storms in situ or after episodes is of great importance although it is difficult to achieve. Efforts have been made by many distinguished researchers to determine the continental dust storms worldwide. According to the aforementioned field measurements and chemical analysis of atmospheric aerosols in this study, Asian dust storm episodes at the Pescadores Islands can be validated by the following criteria: (1) strong northward wind in the cold front system, (2) abrupt increase of $\mathrm{PM}_{10}$ concentration, particularly $\mathrm{PM}_{2.5-10}$; (3) the increase of $\mathrm{C} / \mathrm{F}$ ratio; (4) significant increase of coarse particle mode in the particle size distribution; and (5) the apparent color of aerosol particles collected on filters changed from dark gray to light brown. Further investigation on the chemical analysis of carbonaceous and 
metallic contents of atmospheric aerosols is required and would be valuable for the validation of Asian dusts on chemical respects.

\section{CONCIIUSIONS}

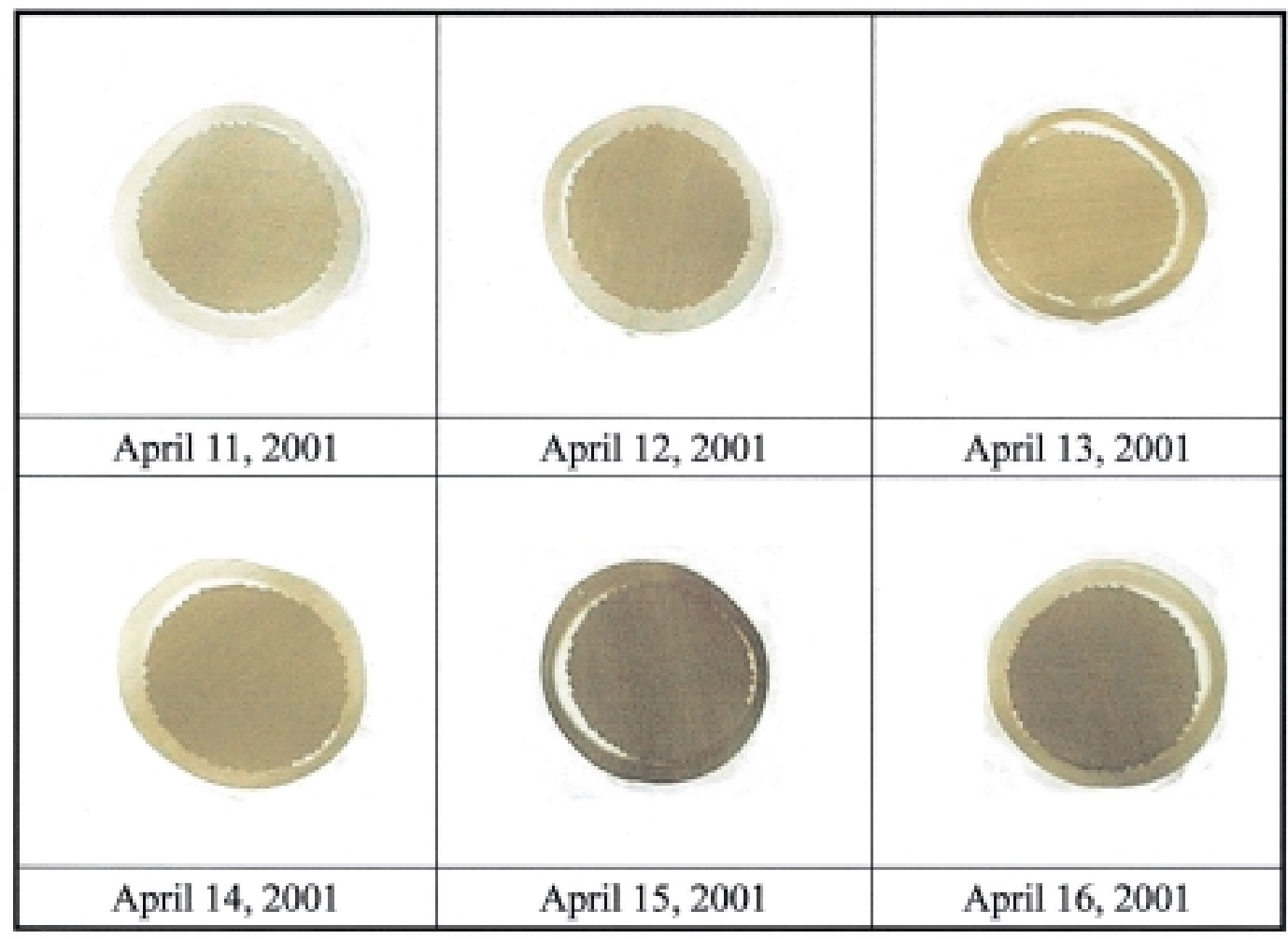

Fig. 14. The apparent color of Asian dusts and local particles collected on filters at the Pescadores Islands.

In this study, five Asian dust storm episodes were determined at the Pescadores Islands on April 12 - 14 and May 2 - 4 in 2001, and March 7 - 9, 18 - 20, and March 31 - April 1 in 2002. It was found that Asian dust storm episodes could last for 2 - 4 days in the Pescadores Islands and Taiwan as well. Asian dust storms invaded Taiwan from either the northeast or the northwest during the sampling campaign. The concentrations of atmospheric aerosols during Asian dust storm episodes were 2 - 3 times higher than the background levels. Asian dust storms could influence both physical and chemical properties of atmospheric aerosols at the Pescadores Islands. Asian dust storms were contributed mainly from coarse particle mode rather than fine particle mode at the Pescadores Islands. Moreover, a significant increase of $\mathrm{SO}_{4}{ }^{2-}, \mathrm{Cl}^{-}, \mathrm{Na}^{+}$, 
$\mathrm{NH}_{4}{ }^{+}, \mathrm{Mg}^{2+}$, and $\mathrm{Ca}^{2+}$ concentration on coarse particle mode was observed for Asian dusts. This suggested that not just natural soil dusts, but also anthropogenic pollutants and oceanic spray could accompany with Asian dust storms. Major chemical species in Asian dusts were ammonium sulfate and sodium chloride except for crustal materials. The criteria for validating the Asian dust storms episodes at the Pescadores Islands were as follows: (1) northward wind with high wind speed at cold front system; (2) abrupt increase of $\mathrm{PM}_{10}$ concentration, particularly $\mathrm{PM}_{2.5-10}$; (3) the increase of $\mathrm{C} / \mathrm{F}$ ratio; (4) significant increase of coarse particle mode in the particle size distribution; and (5) the apparent color of aerosol particles collected on filters changed from dark gray to light brown.

Acknowledgements This study was performed under the auspices of National Science Council, Academia Sinica, and Environmental Protection Administration, R.O.C.. The authors would like to express their sincere appreciation for their financial support to undertake this study. Special thanks go to Dr. Shaw Liu in the Institute of Earth Science at Academia Sinica and Prof. N. H. Lin in the Department of Atmospheric Sciences at National Central University for their constant supports in providing aerosol samplers.

\section{REFERENCES}

Chang, S. C., and T. Y. Yang, 2002: Forecasting the influence of dust storms on the ambient air quality of Taiwan. Proc. Cross-Strait Conf. on Dust Storms, Taipei, Taiwan, 125141. (in Chinese)

Chen, C. T. A., J. T. Wu, B. J. Wang, and K. M. Huang, 2004: Acidification and trace metals of lakes in Taiwan. Aqua. Geochem., 10, 33-57.

Chou, C. C. K., C. Y. Lin, T. K. Chen, S. C. Hsu, S. C. C. Lung, S. C. Liu, and C. Y. Young, 2004: Influence of Long-Range Transport Dust Particles on Local Air Quality: A Case Study on Asian Dust Episodes in Taipei during the Spring of 2002.TAO, 15, 881-899.

Chou, C. K., and T. K. Chen, 2002: Evolution of aerosol size distribution during a dust-storm event. Proc. $6^{\text {th }}$ Inter. Aerosol Conf., Taipei, Taiwan, 1265-1266.

Hsu, S. C., S. C. Liu, C. Y. Lin, R. T. Hsu, Y. T. Huang, and Y. W. Chen, 2004: Metal Compositions of $\mathrm{PM}_{10}$ and $\mathrm{PM}_{2.5}$ Aerosols in Taipei during Spring, 2002. TAO, 15, 925-948.

Kagawa, M., K. Ishzaka, and K. Ohta, 2001: Chemical composition of aerosols over the Sea of Japan in winter. Proc. $2^{\text {nd }}$ Asian Aerosol Conf., Pusan, Korea, 3-4.

Lee, S. B., G. N. Bae, Y. P. Kim, K. C. Moon, 2001: Characteristics of PM ${ }_{2.5}$ measured at Tokchok Island in the Yellow Sea. Proc. $2^{\text {nd }}$ Asian Aerosol Conf., Pusan, Korea, 187188.

Lin, C. Y., S. C. Liu, C. C. K. Chou, T. H. Liu, C. T. Lee, C. S. Yuan, C. J. Shiu, and C. Y. Young, 2004: Long-Range Transport of Asian Dust and Air Pollutants to Taiwan. TAO, 15, 759-784. 
Liu, C. M., 2002: Weather pattern influencing Taiwan' air quality during continental dust storm periods. Proc. Cross-Strait Conf. on Dust Storms, Taipei, Taiwan, 41-61. (in Chinese)

Liu, S. H., and C. S. Yuan, 2000: Source apportionment and optical properties of atmospheric aerosols in metro Kaohsiung, Master Thesis, Inst. Environ. Engine., Nat. Sun Yat-sen Univ. (in Chinese).

Liu, T. H., C. Y. Lin, and S. C. Liu, 2002: Contribution of long-range transport of aerosols to the $\mathrm{PM}_{10}$ concentrations in Taiwan. Proc. $6^{\text {th }}$ Inter. Aerosol Conf., Taipei, Taiwan, 761-762.

Lung, S. C. C., C. H. Liu, S. Y. Huang, T. J. Lin, C. C. K. Chou, and S. C. Liu, 2004: Watersoluble Ions of Aerosols in Taipei in Spring 2002. TAO, 15, 901-923.

Ma, C. J., M. Kasahara, S. Tohno, R. Holler, and T. Kamiya, 2001: Chemical composition of single raindrops fallen in yellow rainfall episode in Japan. Proc. $2^{\text {nd }}$ Asian Aerosol Conf., Pusan, Korea, 185-186.

Peng, C. M. and N. H. Lin, 2002: Long-range transport of Asian dust: an integrated modeling study. Proc. $6^{\text {th }}$ Inter. Aerosol Conf., Taipei, Taiwan, 663-664.

Sun, Y. C., 2002: Characteristics of yellow rain sampled in Taipei. J. Environ. Protection Soc., 25, 88-99. (in Chinese)

Taiwan Power Company, 2003: Ambient air quality monitoring at Guo-Yet in Pescadores, personal contact.

Terada, H., H. Ueda, Z. Wang, 2002: Trend of acid rain and neutralization by yellow sand in East Asia - a numerical study. Atmos. Environ., 36, 503-509.

Tsuang, B. J., C. T. Lee, Y. C. Lin, M. T. Cheng, N. H. Lin, and C. L. Chen, 2002: Mechanisms for quantifying the subsidence of air pollutants from the free troposphere during Asian dust-storm periods. Proc. $6^{\text {th }}$ Inter. Aerosol Conf., Taipei, Taiwan, 667-668.

Uno, I., S. Satake, N. Sugimoto, A. Shimizu, and G. R. Carmichael, 2002: Characteristics of springtime Asian dust transport in 2001 simulated by chemical weather forecasting system CFORS. Proc. $6^{\text {th }}$ Inter. Aerosol Conf., Taipei, Taiwan, 7-8.

Wang, C. C., C. S. Chang, C. T. Lee, and S. C. Liu, 2002: Aerosol characterization at Taiwan's northern tip during ACE-ASIA. Proc. $6^{\text {th }}$ Inter. Aerosol Conf., Taipei, Taiwan, 13-14.

Yuan, C. S., M. H. Hwang, S. W. Chang, and Y. C. Lin, 2001: The influence of continental dust storm on the characteristics of suspended particles in Pencadors Islands. Proc. $9^{\text {h }}$ Aerosol Conf. CAART, Yunling, Taiwan, 231-236. (in Chinese)

Yuan, C. S., J. S. Yuan, C. H. Hung, and C. Yuan, 1999: Temporal and spatial distribution of $\mathrm{PM}_{2.5}$ and $\mathrm{PM}_{10}$ in South Taiwan. Proc. $92^{\text {nd }}$ A\&WMA Ann. Meeting, St. Louis, Missouri, USA.

Yuan, C. S, M. H. Hwang, and C. C. Sau, 2002: Characteristics of atmospheric aerosols sampled at Pescadores Islands during continental dust storm periods. Proc. $6^{\text {th }}$ Inter. Aerosol Conf., Taipei, Taiwan, 1213-1214.

Zhang, X. Y., and Z. S. An, 1999: Source, emission, transport, deposition of Asian dust and global change. Proc. $1^{\text {st }}$ Asia Aerosol Conf., Nagoya, Japan, 133-134.

Zhang, R. J., and M. X. Wang, 2001: Focus on aerosol researches in China. Proc. $2^{\text {nd }}$ Asian Aerosol Conf., Pusan, Korea, 185-186. 